Dossiê

\title{
Bourdieu, Colonialismo e Migração $0^{1}$
}

Steven Loyal ${ }^{2}$

Resumo: Os primeiros trabalhos de Bourdieu sobre a Argélia foram surpreendentemente negligenciados, em grande parte por causa de qualquer discussão sobre os conceitos-chaves que mais tarde definiriam seu trabalho: habitus, capital e campo. No entanto, este trabalho, que fundamentalmente moldaria seu trabalho subsequente, desenvolveu relatos iniciais, embora não desenvolvidos, sobre colonialismo, racismo e migração. Este artigo argumentará que a discussão de Bourdieu sobre o colonialismo em seus primeiros trabalhos, juntamente com os argumentos desenvolvidos por seu aluno e co-autor, Abdelmalek Sayad, fornecem o início de uma base para a compreensão dos processos contemporâneos de dominação e migração.

Palavras-chave: Bourdieu pós-colonial; colonialismo; migração

\section{BOURDIEU, COLONIALISM AND MIGRATION}

Abstract: Bourdieu's early work on Algeria has surprisingly been neglected, largely because of any discussion of the key the concepts that were to later define his work: habitus, capital and field. Nevertheless, this work, which was to fundamentally shape his subsequent oeuvre, developed nascent though undeveloped accounts of colonialism, racism, and migration. This paper will argue that Bourdieu's discussion of colonialism in his early work, together with arguments developed by his student and co-author, Abdelmalek Sayad, provide the beginning of a basis for understanding contemporary processes of domination and migration.

\footnotetext{
Artigo traduzido do original em inglês por Breilla Zanon. Revisão técnica de Angelo Martins Jr.

2 School of Sociology of University College Dublin - Dublin - Irlanda - steven.loyal@ucd.ie
} 
Key-words: post-colonial Bourdieu; colonialism; migration.

\section{Introdução:}

A Argélia foi colonizada pela França em 1830. Em 1848, era legalmente uma extensão do território francês e, portanto, teoricamente tinha o direito de ser governada sob os princípios humanísticos do iluminismo baseados nos direitos do homem (HEARTFIELD, 2002). A realidade do domínio colonial diferia de forma assombrosa. A subordinação da economia argelina às necessidades e interesses econômicos da França foi estabelecida por meio da introdução de uma nova forma de agricultura capitalista, transformando as estruturas das propriedades da terra. Tal fato foi complementado por uma tentativa de conversão ideológica por atacado de "corpos e almas" argelinos por meio da imposição de relações e valores sociais europeus. Finalmente, esses processos socioeconômicos foram combinados com projetos de reassentamento forçado ou reagrupamentos voltados para a pacificação. Essa política tríptica, que resultou na profunda destruição econômica, social e física do campesinato argelino, foi intensificada pelo início da violência feroz durante a Guerra de Independência da Argélia (1956-62), onde estima-se que cerca de 400 mil foram mortos (LE SEUER, 2001: 1).

Foi neste amplo contexto que Bourdieu começou seu trabalho de campo na Argélia. De certa forma, é possível entender sua tentativa sociológica de fornecer uma rigorosa análise científica social da vida argelina como base para informar uma prática política viável empregando a estrutura que ele havia usado em seu estudo de Heidegger (BOURDIEU, 1990a). Utilizou-se do trabalho deste último como o produto de uma sobreposição entre dois campos semiautônomos relacionados: o campo intelectual e político. Esta avaliação, no entanto, requer duas qualificações relacionadas. Primeiro, há uma reflexividade sociológica e epistêmica na abordagem de Bourdieu que, juntamente com seu trabalho de campo, fornece a base para uma análise científica que está completamente ausente do conservadorismo revolucionário de Heidegger; e, em segundo lugar, precisamos entender o papel que a trajetória pessoal e social de Bourdieu desempenhou na formação de seu trabalho subsequente (2004c), ao mesmo tempo em que ele evitava aquilo que chama de "ilusão biográfica" (1987).

O campo intelectual francês incluiu tanto a sociologia como a filosofia, mais expressivamente presentes nos trabalhos de Levi Strauss e Sartre. O campo político incorporou a operação do Estado francês e a guerra na Argélia. A decisão de Bourdieu de realizar um trabalho de campo sistemático sobre as duras 
realidades e a política brutal de "pacificação" e "reassentamento" encaminhadas pelas autoridades francesas coloniais, o separou de outros intelectuais que escrevem sobre a guerra. Como ele observa, sua conversão de uma disciplina de alto status como a filosofia para a etnologia e, eventualmente, para a sociologia, foi uma reação à teoria abstrata, acadêmica e especulativa da filosofia e das ciências sociais durante a guerra e por causa de seu próprio contexto social marginalizado. Isso significava que:

Eu não poderia me contentar com apenas ler livros e visitar bibliotecas em uma situação histórica em que a cada momento, a cada declaração política, a cada discussão, a cada petição, toda a realidade estava em jogo, era absolutamente necessário estar no coração de eventos e formar a própria opinião, por mais perigoso que possa ter sido - e que foi (HONNETH et al., 1986: 39).

O peso da situação de guerra não só precipitou uma mudança da filosofia, mas, juntamente com o seu trabalho sobre campesinato de Bearn (BOURDIEU, 2004b: 438), também o levou ao desenvolvimento de uma reflexividade epistêmica que lhe permitiu alcançar um delicado equilíbrio entre a ciência e a política e evitar o paradoxo em que "as boas intenções costumam fazer muita sociologia ruim" (BOURDIEU, 1990a: 5 ).

Em seu primeiro livro, The Algerians, escrito em 1958 (reimpresso e expandido em 1961), Bourdieu fornece um resumo rico e detalhado e uma visão geral da sociedade argelina. ${ }^{3}$ No entanto, além da enorme visão empírica do livro, que, juntamente com seu trabalho, Travail et travailleurs en Algérie (BOURDIEU et al., 1963), e Le Deracinement (1964), com Abdelmalek Sayad, tinha como objetivo fornecer uma base para o subsequente desenvolvimento de seu quadro de conceitos, este livro inicial também fornece uma série de informações importantes, embora muitas vezes pouco desenvolvidas, sobre questões de cultura, etnia e racismo. Estas geralmente não são áreas consideradas em meio à sua obra. ${ }^{4}$ Em vez disso, seu trabalho, especialmente no Reino Unido, foi lido como o de um teórico social que também se concentrou na reprodução, cultura, consumo e poder educacional. Em particular, sua associação com a teoria social foi resultado de uma preocupação inútil com as discussões conceituais de binários, como subjetividade e objetividade, agência e estrutura, que caracterizaram o

3 Embora não baseado em seu trabalho de campo, o livro inspirou fortemente a economia agrária de J. Berque, E. Dermengehm e C. A. Julian. Veja Bourdieu, Logic of Practice (1990), especialmente o prefácio. A segunda edição contém um ensaio importante "revolução dentro da revolução" do Espirit escrito em 1961. 
campo sociológico britânico durante os anos 80 e 90 (LEAL, 2003). No entanto, é mais razoável ver a sociologia de Bourdieu guiada por questões, agendas e problemas de pesquisa específicos, embora teoricamente consistentes. Ainda que sua análise da Argélia tenha envolvido um objeto específico de pesquisa, seus achados foram generativos e generalizáveis. Como ele mesmo notou em outro lugar:

Através da minha análise de um caso histórico, ofereço um programa para outras análises empíricas realizadas em situações diferentes daquela que estudei. É um convite a uma leitura generativa e à indução teórica que se generaliza a partir de um caso particular bem construído... Husserl costumava dizer que é preciso mergulhar no caso particular para descobrir o invariante dentro dele (BOURDIEU, 1991a: 255).

Apesar do fato de que os conceitos de habitus, campo, capital e prática não aparecem como aspectos integrantes de seus primeiros escritos, será argumentado aqui, ao mesmo tempo evitando uma leitura superdeterminada, que o trabalho inicial de Bourdieu fornece uma série de insights sociológicos sobre as relações sociais que envolvem etnicidade, "raça" e migração, que não foram mais tocadas em seus escritos posteriores. Quero argumentar que, essas ideias, muitas das quais foram desenvolvidas com sucesso no trabalho de Abdelmalek Sayad, nos proporcionam a possibilidade de usar o arcabouço conceitual de Bourdieu para entender as relações etnoraciais e os processos de migração.

\section{Interpenetração cultural e formação grupal}

Os primeiros quatro capítulos de The Algerians fornecem descrições das diferentes características demográficas, socioeconômicas e culturais dos vários grupos étnicos que vivem na Argélia, incluindo principalmente os povos kabyles, shawia, mozabitas e árabes. A família estendida constitui a base central para estes vários grupos. $\mathrm{O}$ forte contexto do grupo comunal e os baixos níveis de individualização também significam que os indivíduos usam uma "personagem em palco" na qual eles agem ou sustentam em "face" para outros. Bourdieu segue esta descrição da base familiar comunal da sociedade argelina com uma discussão sobre "patrimônio cultural comum", interpenetração cultural e formação grupal. A interpenetração cultural, bem como a disseminação de valores culturais entre os vários grupos - incluindo os berberes, os árabes, os caqui e os beduínos - faz parte de um "mecanismo caleidoscópico". Embora eles compartilhem 
um grande acordo em comum, incluindo religião e estrutura familiar, esses vários grupos tentam manter ou acentuar pequenas diferenças entre eles:

Assim, nenhum grupo escapa a esta interpenetração cultural intensa e não existe um grupo que não procure dar-se uma personalidade distintiva, enfatizando certos aspectos do patrimônio cultural comum, o resultado é que, enquanto alguns temas se destacam em relação a essa tapeçaria de entrelaçamento de linhas, eles sempre fazem isso como uma sombra sobre a sombra... Se, de fato, é um fato que a sociedade está organizada de acordo com o mecanismo caleidoscópico, então fica claro por que apresenta esses aspectos contraditórios da diversidade e uniformidade, unidade e multiplicidade (BOURDIEU, 1961 [1958]: 93-4).

As semelhanças estruturais e culturais levam os grupos a empregar estratégias destinadas a construir diferenças. A criação de grupos (1987b) envolve agentes ativos que perseguem uma lógica de diferenciação.

Bourdieu expande a discussão sobre interpenetração e contágio cultural ao examinar essas questões em termos de choque de civilizações entre uma sociedade argelina tradicional e a civilização europeia. $O$ contato entre uma civilização altamente industrializada com um sistema econômico desenvolvido e uma civilização rural tradicional não mecanizada teria levado ao declínio desta última em qualquer circunstância, mas as relações de poder marcadamente diferentes aceleraram o processo. Em contraste com as diferenças culturais construídas de grupos étnicos argelinos relativamente iguais, uma dinâmica diferenciada de poder significava que: "o europeu gradualmente criou um ambiente que refletia sua própria imagem e era uma negação da ordem tradicional, um mundo no qual ele não mais sentiu ser ele próprio um estranho e em que, por uma inversão natural, o argelino foi finalmente considerado o estranho" (BOURDIEU, 1961 [1958]: 131).

A política de assimilação e integração, que os argelinos enfrentariam mais tarde na França, tomou forma no contexto colonial. A tentativa de assimilar os argelinos aos valores europeus implicou na recusa de reconhecer o primeiro como tendo uma cultura original em alguns casos, ou como possuindo uma completamente diferente e negativa, em outros. Ambas as respostas foram resultado da diferença de poder entre colonizados e colonizadores:

Não é por acaso que o colonialismo encontrou o seu último refúgio ideológico no discurso integracionista; de fato, o conservadorismo e a assimilação se opõem apenas na aparência. No primeiro caso, invoca-se diferenças de 
fato para negar a identidade dos direitos e, no outro caso, negam-se diferenças de facto em nome da identidade de direitos. Ou então, alguém concede a dignidade do homem, mas apenas ao francês virtual; ou então é preciso que essa dignidade seja negada invocando a originalidade da civilização norte-africana, mas uma originalidade totalmente negativa, definida pela ausência... Os políticos e os funcionários administrativos ou militares não podem conceber nenhuma generosidade maior do que conceder aos argelinos o direito de ser o que deveriam ser, portanto, à imagem do europeu, o que equivale a negar o que são de fato, na sua originalidade como um povo particular, participando de uma cultura singular. Sendo assim, pode-se, em nome das mesmas racionalizações, deixar o que são, abandoná-los com o intuito de subordiná-los ou conceder-lhes a dignidade de estarem condicionados a deixar de ser o que são (BOURDIEU; SAYAD, 2004 [1964]: 460).

A segregação espacial e social entre os colonizadores europeus, os colonos e seus descendentes (pied noirs) e os argelinos nativos, foi baseada tanto em fatores econômicos como culturais, nos quais muitos argelinos viviam na pobreza. A operação de uma profecia auto-realizável, a performatividade dos atos de fala e do discurso, e as consequências não intencionais das ações coloniais dominantes reforçaram a segregação espacial e social que existia entre eles. A enorme diferença de poder entre os dois grupos era encontrar expressão por meio da casta rígida, assim como relações entre eles:

Considerado do ponto de vista sincrônico, a sociedade colonial nos faz pensar em um sistema de castas. Ela é, de fato, composta por duas "comunidades" justapostas e distintas... A adesão a cada uma dessas comunidades é determinada pelo nascimento; a marca da associação é a aparência física ou às vezes a roupa ou o nome de família. $O$ fato de nascer dentro da casta superior confere automaticamente privilégio, e isso tende a desenvolver um sentimento de superioridade natural na pessoa que se beneficia dessas vantagens... As duas sociedades são colocadas em uma relação de superioridade e inferioridade e são separadas por muitas barreiras invisíveis, criadas por instituições ou por autodefesa espontânea... Por isso, uma segregação racial de fato se desenvolveu. A função do racismo não é senão a racionalização do estado atual das coisas, para que pareça ser uma ordem legalmente instituída (BOURDIEU, 1961 [1958]: 133).

Para Bourdieu, as diferenças extremas de poder influenciaram a autopercepção, ou o que mais tarde ele chamaria de habitus, de todos os atores envolvidos 
quando grupos dominados passaram a se ver através dos olhos do dominante (veja também ELIAS; SCOTSON, 1994 ). Os estereótipos dos argelinos como sendo ignorantes e incompetentes, e dos europeus como posições de prestígio e poder, tornam-se estruturas generalizadas para interpretar o comportamento uns dos outros: "o sistema colonial pode funcionar corretamente apenas se a sociedade dominada estiver disposta a assumir a natureza ou a própria essência negativa" ( $\mathrm{O}$ árabe não pode ser educado, é desleixado etc.) que a sociedade dominadora sustenta como seu destino (BOURDIEU, 1961 [1958]: 134).

Em contraste, e novamente por causa de seu maior poder, o europeu tinha uma imagem mais lisonjeira:

A imagem que o indivíduo da casta dominada formara do indivíduo da casta dominante era composta de certos conceitos básicos. Por um lado, os argelinos, particularmente os argelinos das classes mais pobres, tendiam a identificar o europeu com todos os superiores sociais. E, por outro lado, ele tendia a perceber todos os membros da sociedade dominante - professor, colonizador, médico, engenheiro, capataz, policial e administrador - de uma maneira indistinta ou sincrética, ou seja, como sendo solidários uns com os outros e indissoluvelmente relacionado com a situação colonial... Em linhas gerais, nessa ocasião a ordem social era tal que a experiência da relação com o chefe ou o superior se sobrepunha e se identificava com a experiência da relação com o europeu. Como consequência, o argelino tendeu a desempenhar o papel do árabe visto pelo francês (BOURDIEU, 1961 [1958]: 160-1).

No entanto, este processo de autoidentificação e avaliação através dos olhos dos mais poderosos não era um simples processo de dominação unidirecional, mas sim um processo complexo e dialético, especialmente no contexto da guerra. A discriminação, a dominação e as amplas desigualdades geradas pela política colonial levaram a um sentimento de resignação e fatalismo entre os argelinos, mas também resultou em ressentimento e revolta. A interpenetração cultural tornou possível a reflexividade social. A chegada de uma nova tradição europeia permitiu aos argelinos avaliar e medir o valor de suas próprias tradições por meio do contraste. Como resultado, as ações argelinas dentro de um contexto de guerra colonial, embora aparentemente semelhante ao comportamento anterior, receberam um novo significado e significância. Foi ao aderir às tradições, códigos de conduta e valores argelinos que os argelinos mostraram a sua recusa e oposição simbólica à ordem e ao colonialismo europeu desde 
então: "qualquer renúncia ao seu modo de vida original teria significado, de fato, uma renúncia de si mesmos e a aceitação de uma fidelidade a outra civilização, isto é, à ordem colonial" (Bourdieu, 1961 [1958]: 155). Aqui, Bourdieu faz um contraste entre o "tradicionalismo colonial" e o "tradicionalismo tradicional":

No primeiro caso, há fidelidade a si mesmo, na segunda oposição aos outros. Em um há adesão interna aos valores oferecidos por uma tradição sagrada, no outro, uma resistência passiva contra a intrusão de valores que estão sendo impostos de fora (BOURDIEU, 1961 [1958]: 94).

Um símbolo dessa resistência foi o uso do véu. Em uma discussão presente em muitos debates contemporâneos sobre o papel do véu, Bourdieu observa como ele funcionou como símbolo de resistência ao colonialismo e suas tentativas de assimilação, e como sinal de fidelidade aos valores argelinos:

o véu tem o papel de símbolo que expressa uma aliança e uma exclusão; é principalmente uma defesa do eu interior e uma proteção contra qualquer intromissão de fora. Mas, além disso, ao usar o véu, a mulher argelina também está criando uma situação de não reciprocidade; como um truque de um jogador, ela pode ver sem ser observada; e é através dela que toda essa sociedade dominada se recusa simbolicamente a estabelecer relações recíprocas, está olhando sem se deixar observar. $\mathrm{O}$ véu é o símbolo mais óbvio deste fechamento sobre si mesmo, e os europeus sempre sentiram isso como algo obscuro. Desta forma, torna-se evidente por que todas as tentativas de assimilação tomaram o descarte do véu como seu principal objetivo (BOURDIEU, 1961 [1958]: 158).

\section{A economia argelina e política de reassentamento}

Tradicionalmente, o comércio na Argélia ocorreu em grande parte por meio de um sistema de troca que estava fortemente regulamentado e enredado por costumes, tradições e regras comunitárias de honra e solidariedade. A imposição de uma economia de mercado baseada na troca monetária abstrata, no individualismo e no cálculo racional sobre os indivíduos, cujas disposições foram formadas em um sistema econômico tradicional de produção, no entanto, serviu para levar à desintegração da vida argelina. Numa discussão que se desenha muito sob o debate de Marx a respeito da acumulação primitiva e a crescente mediação das relações sociais pelo mercado, assim como a discussão de Weber sobre a racionalidade econômica e o contraste entre economias tradicionais e 
modernas, Bourdieu argumenta que o capital começou a dissolver as relações pessoais com base em honra e prestígio, que antigamente existiam entre o fazendeiro e sua família e a tribo. Além disso, a introdução de um sistema de crédito e o aumento da concorrência resultaram na consolidação das grandes fazendas e no desaparecimento das menores. Ocorreu um processo de "descampesinato" em que os agricultores se tornaram meeiros trabalhando em outras terras ou forçados a se tornar parte do proletariado rural sem terra, subproletariado ou parte dos desempregados.

Esse deslocamento foi conjugado com uma política colonial de reassentamento forçado e "reagrupamento". A política de reassentamento inicialmente havia sido concebida para cumprir um papel duplo, embora contraditório: primeiro, era vista como uma forma dos militares controlarem e "pacificarem" as comunidades argelinas, destruindo a base organizacional e espacial de sua estrutura social; em segundo lugar, foi concebida para "civilizar" e integrar seus ocupantes à regra administrativa francesa. Durante a guerra, no entanto, a política também serviu como um meio para prevenir a resistência e para frustrar o recrutamento de apoiadores pelo FLN (Front de Liberation National). O número de assentamentos forçados aumentou drasticamente durante a guerra à medida que milhões de argelinos foram forçados a centros de reassentamento, "zonas proibidas", ou deslocados:

O povo argelino foi submetido a uma verdadeira diáspora. O deslocamento forçado ou voluntário dos povos assumiu proporções gigantescas. $\mathrm{O}$ número de pessoas que já não habitam o lar em que viviam em 1954 pode ser estimado aproximadamente em cerca de 3 milhões, se levarmos em consideração os movimentos que ocorreram como resultado do reassentamento das comunidades e do êxodo para as cidades e cidades. Isto significa que aproximadamente um argelino de cada três já não vive em sua antiga residência. (BOURDIEU, 1961 [1958]: 163)

O reassentamento representou uma objetivação das estruturas mentais dos militares franceses na vida argelina. Era um meio dos militares disciplinarem o espaço, assim como era uma forma para disciplinar as pessoas, mas racionalizando isso como um processo civilizador. A expropriação do campesinato de seu ambiente familiar resultou em sentimentos de "desgosto, angústia e desespero". Quase todos sentiram sua remoção forçada como uma separação no sentido mais forte do termo; atingidos em seu âmago, deram vazão a suas 
indignações e desespero (a palavra não é muito forte) com uma voz de sofrimento infeliz" (BOURDIEU, 1961, 1958). Como um resultado:

a vida parece não ter nada estável ou durável para oferecer à população urbana, que foi completamente e irrevogavelmente cortada de seu ambiente anterior, vidas entulhadas em habitações inacreditavelmente insalubres e lotadas nos distritos da cidade velha ou nas novas favelas, e geralmente preenchidas com incerteza quanto ao futuro. A miséria e a insegurança foram pioradas pelo sofrimento resultante da perda de laços grupais em que a estabilidade psicológica e social do indivíduo se baseava nas comunidades antigas (BOURDIEU, 1961 [1958]: 141).

Intensificando os efeitos da deslocação econômica, a política de reinstalação acelerou uma mudança de uma sociedade rural de trabalhadores agrícolas, incluindo fellahs (camponeses árabe) e trabalhadores agrícolas, para uma sociedade caracterizada pelo desemprego e um subproletariado condenado à ociosidade ou forçado a vender sua força de trabalho aos agricultores coloniais e pequenos comerciantes. Embora a vida como camponeses tenha sido difícil, não só porque eles estavam sujeitos a um trabalho duro, aos caprichos do clima e do solo, mas existia até então, pelo menos, um apego à terra e algum controle sobre o processo de trabalho. Contudo, isso se destruiu com o desarraigamento de sua vida:

À totalidade de suas existências faltava o que normalmente constituiu o seu quadro principal: o trabalho diário na ocupação habitual, com seus ritmos temporais e espaciais, as exigências que ele impõe, a segurança que oferece, o futuro que permite imaginar e planejar... Eles inevitavelmente se reconciliaram e se acostumaram a uma forma de existência parasitária e vegetativa (Bourdieu, 1961 [1958]: 179).

\section{A revolução dentro da revolução}

A segunda edição do The Algerians incluiu um capítulo intitulado "A revolução dentro da revolução", que foi originalmente publicado em Espirit como resposta ao livro de Fanon, The Dying Colonialism (1965). Bourdieu compartilhava da crença de Fanon e Sartre de que o sistema colonial só poderia ser destruído em grande escala, de modo que "só uma revolução pode abolir o sistema colonial, que qualquer mudança a ser feita deve estar sujeita à lei de tudo ou nada" (Bourdieu, 1961 [1958]: 146). No entanto, ele também divergia da visão desses 
autores. A violência anticolonial não era uma força emancipadora que simplesmente apagaria a identidade colonial e atuaria como um processo de redenção e autovalidação que libertaria os camponeses argelinos simultaneamente dos valores europeus e do jugo do tradicionalismo islâmico. Isso, para Bourdieu, era uma especulação grosseiramente irresponsável. O trabalho empírico de campo indicou que a religião islâmica continuou a desempenhar um papel muito mais forte na identidade argelina do que Fanon queria reconhecer. Ela impregnou todos os aspectos da vida argelina desde o nascimento até a morte, e incorporou cerimônias islâmicas, costumes, proibições e lei corânica. No entanto, esta não era uma simples visão monolítica da religião como uma força tradicional, embora muitas vezes fosse apenas isso. A religião islâmica era um texto amplo a partir do qual grupos seletivamente desenhavam certos aspectos para atender a seus interesses. A questão sociológica tornou-se então uma análise estrutural do porquê e da forma como os grupos aproveitaram e valorizaram certos aspectos da religião e descartaram os outros:

O islamismo histórico é totalmente o oposto de uma realidade monolítica nas quais se podem distinguir tendências profundamente diferentes e contraditórias (modernistas, tradicionalistas, secularistas, reformistas). Assim, parece que a verdadeira religião de uma civilização foi o resultado de uma seleção, uma seleção que ilustraria a totalidade das escolhas (conscientes ou inconscientes) que esta civilização faz pelo próprio fato de sua existência (Bourdieu, 1961 [1958]: 110).

Fanon também não conseguiu registrar as especificidades que caracterizavam a situação argelina, uma vez que ele havia imposto indevidamente sua relação com o mundo social, sobre o objeto que ele estava discutindo. $\mathrm{O}$ uso de Fanon do racismo corpóreo como conceito para entender o colonialismo na sociedade argelina foi um exemplo:

Existe uma especificidade do racismo contra os negros, que é muito particular. Existem propriedades corporais. . . Este é um racismo absoluto. No caso argelino... os problemas de identidade corpórea que Fanon articulou em relação aos negros não se manifestam da mesma forma. Nunca ouvi falar de um argelino apresentar seus problemas nos mesmos termos que os negros. Existe com certeza um tratamento inferior, etc., mas não com base na identidade corpórea, como Fanon escreve. Eu acho que isso é muito importante... Os problemas dos negros não são os mesmos que os problemas da Argélia. Para os argelinos, há pobreza, humilhação, franqueamento 
e questões linguísticas, mas não estão concentrados no grau em que Fanon reivindica a corporeidade. Há uma enorme diferença... As mulheres argelinas têm um relacionamento com seu corpo que não é o mesmo. Eu acho que a lógica que Fanon desenvolve não tem a mesma importância para os norte-africanos [Maghrebins], como acontece para ele. (BOURDIEU apud LE SEUER, 2001: 253).

A aplicação, o significado e a função do conceito de "racismo" são construídos, contestados e vinculados a contextos determinados e seu uso precisa ser especificado ou delineado em diferentes momentos e locais. A definição também tem que levar em conta as características físicas do corpo, cultura, classe, linguagem e as diferentes ponderações que são dadas em vários contextos. Essas questões foram perspicazmente tratadas por Loic Waquant (1997). ${ }^{5}$

Bourdieu era igualmente crítico em relação à inspiração maoísta de Fanon e sua visão exagerada sobre o potencial revolucionário do campesinato. Aqui, com base na discussão de Husserl sobre a consciência temporal no livro On the Phenomenology of the Consciousness of Internal Time (1990) e na discussão de Merleau-Ponty sobre a "liberdade" na Phenomenology of Perception (1962), ${ }^{6}$ Bourdieu argumentou que a posição material precária dos camponeses os impediu de planejar um futuro, pois eram: "pessoas sem um passado e sem futuro, tentando desesperadamente conquistar um presente que irremediavelmente escapou deles" (BOURDIEU, 1961 [1958]: 184).

A pobreza material dos camponeses era acompanhada por uma pobreza moral. Presos entre dois mundos e aceitos ou em casa, ou em nenhum deles: "este homem, lançado entre dois mundos e rejeitado por ambos, vive uma espécie de dupla vida interior, está preso à frustração e ao conflito interno, com o resultado de que ele está constantemente sendo tentado a adotar uma atitude

5 Devido à sua natureza polêmica e contestada do racismo como um conceito popular politizado, Waquant argumenta que o termo deve ser abandonado. Em vez disso, ele defende uma análise da dominação racial que abrange o espectro das formas sociais, da cognição e da interação ao espaço e às instituições, que são: categorização (incluindo classificação, preconceito e estigma), discriminação (tratamento diferencial com base na associação de grupo imputada), a segregação (separação grupal no espaço físico e social), a guetização (o desenvolvimento forçado de estruturas sociais e organizacionais paralelas) e a violência racial (que vão desde intimidação interpessoal e agressão até linchamentos, tumultos e massacres e clímax com guerra racial e extermínio). Esses mecanismos básicos de subordinação etnoracial entram em combinações móveis em diferentes sociedades e em diferentes períodos dentro de uma mesma sociedade, de modo que, em qualquer ponto, cada grupo é confrontado com um perfil particular de dominação racial (1997: 230).

6 Ver especialmente a seção que descreve as diferentes condições em que um trabalhador diário, um fazendeiro inquilino e um trabalhador da fábrica podem se tornar revolucionários conscientes da classe. (MERLEAU-PONTY, 1962: 443-455). 
de identificação excessiva ou de negativismo rebelde" (BOURDIEU, 1961 [1958]: 144). Mais uma vez, este processo de resignação teve um contraponto dialético, por vezes, resultando no oposto de sua intenção: indivíduos ressentidos que foram forçados a estarem juntos, transcenderam suas diferenças tribais sob um espírito de solidariedade, nacionalismo e revolta contra sua desapropriação. Isso constituiu a base para o amplo apoio argelino à guerra.

\section{Sayad e emigração}

Em Deracinement (1964), bem como em um ensaio deste livro, Cultural Sabir (2004 [1964]), ambos escritos com Abdelmalek Sayad, Bourdieu argumentou que a deslocação econômica e o reassentamento militar forçado levaram à uma migração interna em grande escala para as cidades e para a migração para a França: "Sem nenhuma outra esperança além de colher o suficiente para sobreviver, os mais destituídos enfrentam a escolha entre o fatalismo dos desesperados (que não tem nada a ver com o Islã) e a partida forçada para a cidade ou para a França" (BOURDIEU; SAYAD, 2004 [1964]: 455). O resultado foi deslocamentos dramáticos da população das regiões rurais e montanhosas para as cidades urbanas.

Em contraste com outras migrações coloniais europeias em larga escala, que geralmente surgiram após a Segunda Guerra Mundial, a migração colonial em larga escala da Argélia para a França existiu desde pelo menos o início do século. Por razões históricas, um número grande e desproporcional de migrantes que foram para a França era da região montanhosa da Kabylia. Durante o período da guerra, a emigração continuou com o número de argelinos que vivem na França crescendo de 211.000 para 350.000 (MACMASTER, 1997). Muitos dos emigrantes anteriores se estabeleceram em Marselha, Lyon, Lorena, Nanterre ou Paris e mantiveram redes ou se agruparam com outros emigrantes. ${ }^{7}$ No entanto, sua chegada foi imediatamente problematizada e surgiram questões sobre a sua assimilação racial, cultural e religiosa ao que foi considerada uma cultura e civilização europeia marcadamente diferente e mais desenvolvida. Esses discursos escolásticos e de mídia racializados forneceram a base para sustentar formas de discriminação etnoracial contra esses migrantes e eventualmente a sua marginalização social.

7 Embora fazendo parte apenas 3,5\% da população, sua chegada foi imediatamente interpretada como problemática com questões relativas à sua assimilação racial e cultural e religiosa e sua adaptação à uma cultura e civilização europeias profundamente diferente e mais desenvolvida, tornando-se imediatamente parte de um discurso educacional racial e educacional (MACMASTER, 1997). 
As discussões de Bourdieu sobre interpenetração cultural, integração e emigração levaram os argelinos que viviam na Argélia ao domínio colonial como seu ponto de referência. Oficialmente e formalmente, pelo menos, a Argélia não foi vista como uma colônia da França, mas uma extensão do seu território. Sayad, no entanto, olha mais profundamente para os argelinos que emigram para a França antes, durante e após a descolonização. Seu trabalho é incomum na medida em que começa, enquanto trabalha com Bourdieu, examinando as contradições do colonialismo francês na Argélia e a proporção de poder desigual que caracteriza essas relações, e depois se concentra nos argelinos que emigram para a França e as contradições e sofrimentos sociais que eles enfrentam (BOURDIEU; WACQUANT, 2000). A mudança de uma análise dos franceses na Argélia para os argelinos na França é, portanto, também uma mudança na dinâmica de poder específica que caracteriza as relações franco-argelinas. No entanto, apesar da descolonização, as relações sociais dos argelinos na França acentuaram o traço da intervenção colonial dos franceses na Argélia. Os efeitos que a emigração e a dominação tinham sobre os argelinos que viviam na França em termos de seu equilíbrio psicossocial, autoidentificação, dissonância cognitiva e deslocamento social e material ou sendo apanhados entre "dois mundos", de certa forma refletia a condição dos argelinos que viviam na Argélia sob o domínio colonial francês. Após sua morte prematura, em 1998, Bourdieu, coletou e publicou muitos dos artigos importantes de Sayad escritos entre 1975 e 1996 na la Double Absence - posteriormente traduzidos como The Suffering of the Immigrant (2004). O título "dupla ausência" mostra a sensação de que esses imigrantes se tornaram fora do lugar e um estrangeiro tanto na Argélia, já que não residiam mais ali, assim como na França, onde também estavam fora de lugar por serem imigrantes. Em um sistema internacional mutuamente exclusivo, eles estão sempre errados. Não representados e sem voz pública, eles sofrem em silêncio.

Como Sócrates, descrito por Platão, o imigrante é atopos, não tem lugar e é deslocado e não classificado. A comparação não se destina simplesmente a enobrecer o imigrante em virtude da referência. Nem cidadão nem estrangeiro, nem verdadeiramente do lado dos seus iguais nem realmente do lado do Outro, ele existe dentro desse lugar "bastardo", do qual Platão também fala, na fronteira entre o ser e o não-ser social. Deslocado no sentido de ser incongruente e inoportuno, ele é uma fonte de constrangimento. A dificuldade que temos em pensar nele - mesmo na ciência, que muitas vezes reproduzem sem perceber, os pressupostos e omissões da visão oficial - simplesmente recria o constrangimento criado por sua insuficiente 
existência. Sempre no lugar errado, e agora como fora de lugar em sua sociedade de origem, assim como na sociedade de acolhimento, o imigrante nos obriga a repensar completamente a questão dos fundamentos legítimos da cidadania e das relações entre cidadão e estado, nação ou nacionalidade. (BOURDIEU, 2004a: XIV).

Embora existam algumas diferenças em suas perspectivas sociológicas, a influência de Bourdieu é evidente em toda a tentativa de Sayad em desenvolver uma sociologia da migração, incluindo uma posição metodológica que engloba uma reflexividade epistêmica. Seu trabalho é, ao mesmo tempo, uma história social do duplo fenômeno da emigração e da imigração e uma história social do discurso sobre o fenômeno em questão (2004: 2). "O argumento central que abarca seu trabalho é que a imigração e a emigração estão intrinsecamente ligadas: os dois componentes formam "aspectos indissociáveis de uma realidade única" (2004: 1). Os sociólogos, ele argumenta, precisam entender tanto o "conjunto de características sociais e as disposições e aptidões socialmente determinadas que os emigrantes dispõem antes da sua entrada na França” (2004: 30), quanto à sua posição após a chegada. Significa que eles precisam entender a formação do habitus tanto dentro dos vários campos sociais, culturais, políticos e econômicos dentro do "país de envio", quanto as mudanças que sofrem nestes campos no "país de acolhimento". Embora o habitus como um sistema de disposições duráveis e transponíveis seja maleável, as experiências precoces foram cruciais para moldar e filtrar experiências posteriores. Ao internalizar condições radicalmente diferentes de existência com base em experiências e disposições antigas, por meio do habitus e suas inscrições no corpo, os migrantes muitas vezes se tornaram social e psicologicamente deslocados ou experimentaram um efeito de "histerese".

Para Sayad, entender o país de origem do migrante, bem como a sua recepção e a sua trajetória social global, não só evita um etnocentrismo residual em que está implícito que a vida de um imigrante começa quando ele entra no país anfitrião, mas facilita um relato da migração que evita cair em uma problemática em que a adaptação do migrante à sociedade hospedeira é priorizada. Em tais considerações, os valores culturais dos migrantes - como parte das lutas sobre a definição legítima da noção de cultura - são geralmente julgados de acordo com os valores do Estado-Nação anfitrião, e invariavelmente julgados como problemáticos, disfuncionais ou como impedimento para a assimilação. As forças estruturais subjacentes ao sistema de migração incluem relações de dominação internacional entre países desenvolvidos e não desenvolvidos. Esta 
macro desigualdade estrutural geopolítica é, muitas vezes, rejustificada nas relações micro entre migrantes e membros da sociedade hospedeira: "o equilíbrio de poder que está na origem da imigração é retraduzido em efeitos que são projetados sobre as modalidades das presenças dos imigrantes", no lugar que lhes é atribuído, sobre o status que lhes é conferido e sobre a posição (ou, para ser mais preciso, as diferentes posições) que ocupam na sociedade que os conta como de facto (se não, de jure) habitantes (SAYAD, 2004: 163).

A ampliação de sua dupla conceitual de emigração e imigração também possibilita discernir três ondas de migração de argelinos para a França e permite um relato mais gradativo e diferenciado do uso do conceito e do próprio processo de migração. Ao dividir a migração argelina em três fases, Sayad também ignora o reconhecimento coletivo geral e a dissimulação do processo migratório - que todos os principais interessados envolvidos (o emigrante, sua comunidade de origem e o estado receptor) são benéficos - bem ora por razões diferentes. Essas ilusões coletivamente compartilhadas - por exemplo, a visão de que a migração argelina era sempre uma migração doméstica normal ou circular, que apenas ocorreu migração trabalhista e que a migração não teve nenhuma consequência política - esconde as duras realidades e os sofrimentos da migração e ajuda a reproduzir o fenômeno.

Correspondendo à uma situação histórica em que se encontravam os camponeses argelinos, uma primeira fase da emigração argelina começou em torno da virada do Século XX e durou até logo após uma Segunda Guerra Mundial. Uma grande proporção da migração predominantemente masculina durante o período de entreguerras foi circular ou noria com aproximadamente meio milhão de argelinos que se deslocaram entre Argélia e França, e assim sucessivamente (MACMASTER, 1997). A maioria procurou recursos econômicos para sua ampla unidade familiar. Uma jornada para a França e o retorno subsequente foram determinados pelos ritmos do calendário agrícola argelino e seguiram ciclos sazonais. O camponês emigrante estava apenas fisicamente ausente da terra argelina e de seu grupo tribal, mas psicologicamente permaneceu ligado à cosmologia camponesa com seus fortes laços com a terra, uma valorização dos rituais de honra e uma submissão ao grupo comunal. Um bom campesino era aquele que mostrava autocontrole e não perdia as virtudes camponesas ao ficar poluído pelos caminhos do morador da cidade, no que diz respeito ao modo de vestir, à comida, ao consumo, ao uso da linguagem etc. Um "camponês autêntico" manteve caminhos camponeses de atuação, pensamento e sensação (SAYAD, 1998).

Uma segunda era de emigração após o "descampesinato" e a proletarização da massa de camponeses argelinos começou em 1948. A política de 
reassentamento forçado e a disseminação de dinheiro como meio de troca - resultante em parte devido à emigração anterior e em parte às remessas enviadas - induziram uma nova forma de emigração. O significado e a função da emigração mudaram à medida que o individualismo crescente também se concretizou. O emigrante agora "apenas parecia ser um camponês, pois tudo relacionado a ele negava os valores tradicionais dos camponeses (aspirações para o trabalho não-agrícola, trabalho em tempo integral e individualismo econômico, mas também individualismo social, urbanização e seu sistema de comportamento, especialmente em termos de consumo)" (SAYAD, 2004: 39). Em vez de emigrar para o grupo para finalmente retornar, o emigrante agora deixou de atender às suas próprias necessidades e procurou um emprego permanente na França. A ruptura com o ethos camponês e a adoção do estilo de vida do habitante da cidade também significava que, quando ele voltava para a família, ele fazia isso como "alguém de férias":

Ele é praticamente um "estrangeiro" em um mundo que parece cada vez mais estranho a ele. Tudo sobre o jeito que ele se comporta - seu uso do tempo, as horas que ele mantém, suas atividades, seus movimentos, suas atividades de lazer, seus hábitos de consumo, seus hábitos alimentares (o número de refeições que ele come, o tempo que ele come, as coisas que ele come), suas roupas - é projetado para lembrar a todos de seu status de emigrante (ou seja, um morador da cidade), de sua posição como "um convidado na sua própria casa” (SAYAD, 2004: 49).

Com a comunidade camponesa argelina cada vez mais incapaz de controlar a emigração, uma mudança de homens adultos solteiros no que diz respeito à reunificação familiar também ocorreu. A oposição entre migração de trabalho e assentamento não deve ser exagerada: o primeiro invariavelmente produz o último.

Logo após a independência argelina, surgiu uma terceira onda de emigração a partir da qual uma comunidade argelina relativamente autônoma começou a se desenvolver na França. Apesar da política da FLN de tentar desencorajar a emigração para a França devido à sua associação anterior com o colonialismo, ela continuou e aumentou rapidamente após a guerra. Em 1973, quando entrou em vigor uma barreira sobre a emigração argelina, havia cerca de 800 mil argelinos na França. A emigração serviu como uma válvula de segurança no contexto de níveis diretos de desemprego e pobreza (MACMASTER, 1997). Nessas "pequenas sociedades de compatriotas", emigrantes viviam na exclusão da sociedade hospedeira e não mantinham vínculos com a terra de seu nascimento: 
"Separados por dois tempos", entre dois países e entre duas condições, toda uma comunidade vive como se estivesse "em trânsito" (SAYAD, 2004: 58).

Sendo condenados a se referir simultaneamente a duas sociedades, os emigrantes sonham sem perceber a contradição, combinando as vantagens incompatíveis de duas escolhas conflitantes. Às vezes, eles idealizam a França e gostariam de ter, além das vantagens que lhes dão (um emprego estável, um salário etc.), essa outra qualidade de ser uma "segunda" terra de nascimento - o que seria suficiente para transfigurar o relacionamento para com o país e para transformar magicamente todos os motivos da insatisfação que experimentam na França. Em outras ocasiões, eles idealizam a Argélia em seus sonhos ou depois de passarem um tempo por lá durante as férias. Eles querem que ela corresponda à uma França idealizada (ou seja, uma Argélia que lhes oferece aquilo que vão à procura na França). (SAYAD, 2004: 58). Para resolver essa contradição existencial, os emigrantes mantêm uma ilusão coletiva de que sua migração era temporária - mas é um "temporário duradouro".

\section{0 estado e a imigração}

Além de enfatizar o papel importante do habitus do emigrante - tanto no país de origem quanto no país hospedeiro - para a compreensão dos processos de migração, Sayad também notou o papel importante que o Estado desempenha na formação e no pensamento sobre a migração. Em seu ensaio Immigration and State Thought, no livro The Suffering of the Immigrant (2004), ele observa que "a virtude secreta da imigração: fornece uma introdução... para a sociologia do estado" (SAYAD, 2004: 279; NOIRIEL, 1996).

Em seus escritos sobre o estado, Bourdieu tende a enfatizar seu poder simbólico. Para Bourdieu, as "estruturas" no mundo social conduzem uma "vida dupla" para que elas existam duas vezes. Primeiro, elas existem na "objetividade da primeira ordem" constituída como posições sociais objetivas - como campos. Em segundo lugar, elas persistem na "objetividade da segunda ordem", sob a forma de sistemas de classificação, feixes subjetivos de disposições depositadas em indivíduos sob a aparência dos esquemas cognitivos que compõem seus pensamentos, sentimentos e conduta. A capacidade de regular a vida social depende em parte da capacidade de sustentar e impor categorias de pensamento por meio das quais as instituições e os indivíduos fazem sentido do mundo. $\mathrm{O}$ Estado realiza três funções por meio do seu discurso institucional oficial:

Primeiro; ele realiza um diagnóstico, função que é, um ato cognitivo que impõe reconhecimento e que muitas vezes tende a afirmar o que uma pessoa 
ou coisa é e o que é universalmente, para todas as pessoas possíveis e, portanto, objetivamente. É um discurso quase divino, que atribui a cada um uma identidade. Em segundo lugar, o discurso administrativo, através de diretrizes, ordens, prescrições, etc., diz o que as pessoas têm que fazer, considerando o que são. Em terceiro lugar, diz o que as pessoas realmente fizeram, como em contas autorizadas, como relatórios policiais. Em cada caso, impõe um ponto de vista, o da instituição, especialmente através de questionários, normas oficiais. Este ponto de vista é configurado como um ponto de vista legítimo, ou seja, como um ponto de vista que todos devem reconhecer pelo menos dentro dos limites de uma determinada sociedade. $\mathrm{O}$ representante do estado é o repositório do senso comum (BOURDIEU, 199ob: 136).

Essas três funções, para Bourdieu, pressupõem que o estado seja capaz de produzir e impor categorias de pensamento, que posteriormente são aplicadas ao mundo social. O Estado participa na forma de "criador de mundo" (GOODMAN, 1978), regulação, autorização e sanção. Assim, os estados não só tentaram monopolizar a força física, a tributação e os meios de movimento, mas também o uso legítimo da força simbólica, incluindo o poder de nomear, categorizar e definir objetos e eventos, dando-lhes um selo oficial de aprovação. ${ }^{8}$

Esse potencial para impor o que Bourdieu chama de "visão de divisões" é o "poder de fazer divisões sociais e, portanto, o poder político por excelência" (BOURDIEU, 1984: 468). A luta política é uma luta cognitiva pelo poder de impor a visão legítima do mundo social - isto é, o poder de (re)fazer a realidade preservando ou alterando as categorias por meio das quais os agentes compreendem e constroem esse mundo.

Apesar de um discurso contínuo e generalizado sobre a globalização e o desaparecimento do Estado, vivemos em um mundo de Estados-Nação crescentes (MANN, 1993: 1997). Sua existência forma o que Bourdieu denomina uma doxa: hipóteses fundamentais inquestionáveis de análise social. O problema fundamental, então, para qualquer sociologia da migração, é analisar a imigração sem simplesmente usar o Estado-Nação como o quadro de referência, e sem implementar de forma crítica ou involuntária as próprias categorias do Estado-Nação, esquemas de percepção, ideologia e seus princípios organizadores (ABRAMS, 1988; BOURDIEU, 1994; CORRIGAN; SAYER, 1985). A tendência anterior foi

8 Bourdieu escreve amplamente e em diferentes aspectos sobre o estado, incluindo suas funções materiais, burocráticas e simbólicas. Veja, inter alia: (1998a: 35-63; 1996; 1998b:1-9; 2004d). 
diagnosticada por Elias (1978), mas mais recentemente foi referida como "nacionalismo metodológico" (WIMMER; GLICK-SCHILLER, 2002).

Para Sayad, a imigração só pode ser compreendida e interpretada por meio de categorias de pensamento estatal que operam com uma divisão constitutiva binária entre "nacionais' e "não nacionais":

É como se fosse da própria natureza do estado discriminar... fazer distinções, sem a qual não pode haver estado nacional, entre os "nacionais" ele se reconhece e, portanto, ele se reconhece assim como se reconhecem nele (esse duplo efeito de reconhecimento mútuo é indispensável para a existência e função do Estado) e aos "outros" com quem trata apenas em termos "materiais" ou instrumentais. Ele só negocia com os outros porque eles estão presentes no domínio da sua soberania nacional e no território nacional abrangido por essa soberania (2004: 279).

Os Estados aspiram a uma homogeneidade nacional total, mas a migração interrompe isso. Portanto, é imperativo que o sociólogo sujeite o pensamento do Estado à reflexão crítica.

Se retornarmos à análise de Boudieu, parece haver dois aspectos inter-relacionados do efeito que as taxonomias e classificações oficiais do estado têm em relação à migração. $O$ primeiro se refere às distribuições objetivas de pessoas no espaço social, que estão ligadas ao status diferente dos migrantes em termos de direitos em contraste com os cidadãos. Em vez de fornecer a todos os residentes os mesmos direitos civis e políticos, os esquemas de classificação burocrática geram padrões sistemáticos de discriminação. As categorias legais e administrativas de "requerente de asilo", "refugiado" e "migrante econômico" são importantes na medida em que conferem diferentes direitos e atribuições de justiça à esses recursos em contraste com os cidadãos. Todos os países de imigração classificam e atribuem migrantes a categorias legais e políticas específicas - ou status de imigração diferenciado em contraste com a cidadania. Esses direitos e recursos incluem: acesso ao bem-estar social, à educação, ao tratamento justo no mercado de trabalho e no local de trabalho, aos serviços sociais, incluindo o serviço de saúde, o direito de voto, de terem familiares vivendo com eles, e de serem tratados de forma igualitária e livre de discriminação em geral. Apesar disso, na realidade, não há um corte dicotômico claro entre cidadãos e não cidadãos nos estados imigrantes ocidentais, mas um contínuo de direitos, com diferentes estatutos legais que conferem direitos diferentes a diferentes categorias de migrantes (HAMMAR, 1990). As classificações estaduais são cruciais na 
determinação dessas alocações diferenciais e no acesso a recursos materiais e, assim, na formatação das vidas dos migrantes.

Em segundo lugar, assim como esses "efeitos objetivos" que ajudam a reproduzir a "objetividade da primeira ordem", as categorias e classificações administrativas utilizadas pelo Estado desempenham um papel importante na definição de processos de autoidentificação, poder simbólico e violência simbólica que reforçam essa exclusão social. Isso não é simplesmente uma influência ideológica ou cognitiva, mas sobre "tudo o que a inserção nativa em uma nação e um estado enterra nas profundidades internas das mentes e dos corpos, em um estado quase natural, ou, em outras palavras, muito além do alcance da consciência" (BOURDIEU, 2004: XIV). A questão da classificação das pessoas e como isso afeta as pessoas classificadas é de imensa importância sociológica (KRIPKE, 1980; BARNES, 1988: HACKING, 2002). Ambos os grupos dominantes e marginalizados podem se definir e se relacionar por meio de tais categorizações. Como Bourdieu observa em A Distinção:

Agentes dominados, que avaliam o valor de sua posição e suas características, aplicando um sistema de esquemas de percepção e apreciação... tendem a atribuir a si mesmos o que a distribuição lhes atribui... ajustando suas expectativas para suas chances, definindo-se como a ordem estabelecida os define (BOURDIEU, 1984: 471).

O efeito da classificação do Estado é especialmente influente em migrantes desempregados em moldar sua autopercepção:

Fazendo uma virtude por necessidade, e em grande parte por causa da posição dominada, ele ocupa a estrutura das relações de poder simbólicas. . Às vezes, ele deve, como imigrante (quando está no fundo da hierarquia social no mundo do imigrante), assumir os estigmas que, aos olhos da opinião pública, criam o imigrante. Ele deve, portanto, aceitar (resignado ou sob protesto, submissa ou desafiadoramente, ou mesmo provocativamente) a definição dominante de sua identidade (SAYAD, 2004: 286).

O fato de ser visto por outros como anômalo ou mesmo "culpado" por carregar um status de imigrante na ordem nacional estabelecida, pode ser internalizado e adotado como parte central da autodefinição do migrante. Essa disposição adquirida na posição ocupada pode levar a um ajuste de "um senso de um lugar". Na França, os descendentes muçulmanos de imigrantes argelinos, que têm cidadania francesa, ainda são definidos e tratados como estrangeiros. 
Como resultado, alguns precisam tranquilizar a população em geral do seu valor moral demonstrando repetidamente sua boa vontade e boa-fé, a fim de antecipar e evitar acusações de adesão aos valores reacionários “islamistas". É por causa dessas acusações moralmente carregadas de desvantagem e as implicações que eles têm para o seu tratamento, que os migrantes empregam "narrativas de defesa", dispositivos que são "projetados especificamente para evitar ou reduzir atribuições de culpa" (SCOTT; LYMAN, 1970: 138- 9). Como foi o caso durante a guerra argelina, reações defensivas podem significar migrantes que participam de estratégias de assimilação:

Isso pressupõe colocar uma grande importância no esforço de sua autoapresentação e representação (a representação que os outros têm dele e a representação que ele deseja dar a si mesmo). O esforço é, portanto, focado essencialmente em seu corpo, sua aparência física... cor da pele, cabelo etc.; sinais culturais como o sotaque, o modo de falar, a roupa, o uso de um bigode (SAYAD, 2004: 286-7).

Mas a estigmatização e a humilhação também podem levar à revolta e à raiva. Essa revolta pode, no entanto, reforçar a caracterização original, como se uma profecia autorrealizável estivesse em operação. $\mathrm{O}$ estigma em si gera uma revolta contra o estigma... consiste em reapropriar ou reivindicar o estigma... de acordo com o clássico paradigma do preto é lindo. Isso pode até levar à instutionalização do grupo, o que, assim, torna o estigma... em sua base" (SAYAD, 2004: 286).

No entanto, ambas as estratégias significam que o migrante, como um "ser que existe para os outros", experimenta sua identidade de forma contraditória: por um lado, como defesa ou protesto para a definição dominante e, por outro, como submissão ou renúncia à essa definição. A questão, para Sayad, no contexto dessas lutas sociais entre o imigrante e a sociedade de acolhimento, não é se o imigrante pode conquistar ou recuperar uma "identidade legítima", seja o que isso possa significar, mas a possibilidade de o migrante construir sua própria identidade e avaliá-la com autonomia relativa. Tal contradição não é simplesmente psicológica, mas se refere ao habitus, é uma contradição incorporada.

\section{Conclusão}

Devido à ausência de conceitos como habitus, campo, capital e prática, os primeiros escritos de Bourdieu sobre a Argélia foram, muitas vezes, interpretados como uma incursão juvenil em uma área de pouco interesse sociológico. Essas obras são amplamente consideradas interessantes para as reconstruções 
escolares ou biográficas de sua trajetória intelectual, mas, de outro modo, têm pouco valor sociológico, visto que elas foram superadas ou retrabalhadas em seu trabalho posterior. Essa visão é enganadora. ${ }^{9}$ Em vez disso, existem argumentos e ideias que, devido à uma questão de pesquisa concreta envolvendo colonialismo e poder na Argélia, são úteis e aplicáveis para a compreensão dos processos sociológicos contemporâneos da dominação social, constituindo um “caso especial do que é possível” (BOURDIEU , 1998a: 2).

$\mathrm{O}$ trabalho inicial de Bourdieu fornece informações sobre as dinâmicas intra e intercultural dentro dos contextos do poder diferencial, bem como uma política de assimilação e integração por meio da imposição de valores sociais, culturais, políticos e econômicos franceses. Ele também discute a aquiescência, demissão e resistência da Argélia a esse processo. $\mathrm{O}$ resultado composto de deslocamento econômico, imposição cultural e reassentamento forçado foi um processo de descampesinado e expropriação. Os camponeses expropriados tornaram-se parte de um subproletariado cada vez maior, forçados a trabalhar como meeiros em fazendas de colonos, ou a emigrar para as cidades ou para a França para encontrar trabalho. A sua miséria material e insegurança foi agravada por agitação emocional e psicológica. Eles se encontraram presos entre dois mundos, mas não se sentiam em casa em nenhum deles. Incorporaram o sistema de crenças contraditórias e a lógica prática de duas cosmologias opostas; cálculo racional individualizado e lucro, por um lado, e comunidade, tradição e honra, por outro.

Abdelmalek Sayad desempenha um papel fundamental no desenvolvimento dos primeiros trabalhos de Bourdieu sobre deslocamento social e emigração na Argélia. Sayad baseia-se no trabalho de Bourdieu de várias maneiras. Primeiro, ele adota uma reflexividade epistêmica em que o discurso sobre a migração é parte do objeto da própria pesquisa. Os discursos leigos e acadêmicos sobre a migração têm implicações performativas e políticas e, portanto, precisam ser examinados ao invés de serem adotados inconscientemente. Olhando para a trajetória integral do migrante, ele se concentra na conexão indissociável entre o emigrante e o habitus imigrante. Finalmente, ele enfatiza a importância da política estatal na determinação da posição de um migrante na estrutura social e na classificação do estado na formação de sua estrutura mental.

A experiência dos argelinos que vivem na França tem uma série de características paralelas à sua experiência sob a colonização francesa. Em ambos os

9 No entanto, uma exceção é a edição especial da revista Ethnography (2004), editada por Loic Wacquant, dedicada à Bourdieu. 
casos, o diferencial de poder contínuo significava que eles eram marginalizados social e economicamente e que ocupavam uma posição dominada no espaço social. Isso continua até hoje. Escrevendo no fim dos anos 90, Bourdieu observa:

É possível resistir à violência que é exercida diariamente, de consciência limpa, por meio da televisão, do rádio e dos jornais, por meio de reflexos verbais, imagens estereotipadas e palavras convencionais, e o efeito que a habituação produz, criando imperceptivelmente, em toda a população, o limiar de tolerância de insultos racistas e desprezo, reduzindo as defesas críticas contra o pensamento pré-lógico e a confusão verbal (entre o islamismo e o islamicismo, entre muçulmanos e islamistas, ou entre islamistas e terroristas, por exemplo), reforçando insidiosamente todos os hábitos de pensamento e herdados há mais de um século do colonialismo e das lutas coloniais. Apenas uma análise detalhada do filme das 1.850.00o "verificações de identidade" recentemente realizada pela polícia para a grande satisfação do Ministro do Interior dariam uma ideia da multidão de humilhações sutis (uso condescendente de buscas corporais em público etc.) ou injustiças flagrantes e ilegalidades (assalto, entrada forçada, violência contra privacidade) infligidas a uma parcela significativa dos cidadãos ou convidados deste país, uma vez que é reconhecido pela abertura aos estrangeiros; e também dar uma ideia da indignação, revolta ou raiva que tal comportamento pode despertar (BOURDIEU, 1998b: 22).

Apesar do fim da colonização na Argélia, os argelinos na França continuam a encontrar-se numa localização ambígua entre duas condições sociais com demandas e disposições contraditórias. As disposições básicas, profundas e familiares incorporadas e os comportamentos habituais adquiridos em estrutura social foram interrompidos, transformadas e desestabilizadas depois de confrontar um conjunto de relações sociais completamente desconhecidas ou totalmente diferentes. A profunda incoerência que caracteriza o seu habitus não só criou grandes angústias e sofrimentos psicológicos, mas também os colocou dependendo das circunstâncias e da sua posição no espaço social, tornando-os resignados e resistentes à violência simbólica inerente das políticas que visam assimilá-los aos valores franceses.

Como todas as estruturas sociológicas generativas, existem algumas áreas nas quais um quadro Bourdieusiano sobre migração e assentamento precisa ser desenvolvido e colocado à prova. Se tomarmos o exemplo dos processos de migração e liquidação na Irlanda como um estudo de caso, algumas dessas 
deficiências e elisões tornam-se claras. Primeiro, embora Sayad olhe para o habitus do emigrante como parte da dupla emigrante-imigrante, há poucas discussões sobre os capitais econômicos, culturais, sociais e simbólicos que os emigrantes possuem antes da sua chegada à sociedade que os acolhe. Também não há uma discussão sobre como isso é medido, traduzido, reconhecido ou afeta-os no novo país de recepção. Em segundo lugar, o processo de classificação estatal em termos de conferir diferentes estatutos de imigrantes legais precisa ser conjugado com a questão da classe e as várias quantidades de capital que o migrante possui como determinante da sua posição no espaço social. Os migrantes com um elevado volume de capital cultural e econômico, tanto na UE como fora da UE, tiveram diferentes experiências de migração e assentamento e tratamento daqueles com baixos volumes de capital. Essa dinâmica de classe também é expressa nas políticas que envolvem a criação e representação de grupos étnicos. Em terceiro lugar, é necessária uma ênfase nas relações de gênero, dado que a continuação da feminização da migração é necessária.

Tomamos o exemplo da migração e do assentamento. Na Irlanda, a posição dos migrantes no espaço social foi moldada por quatro fatores principais: 1) o seu habitus prévio e nível e tipo de capital que possuíam; 2) a política de estado e o modo de classificação do estado; 3) o nível de discriminação e discriminação etnoraciais que enfrentaram do estado e da população de acolhimento; e 4) a economia política na Irlanda (LEAL, 2003a).

Assim, Bourdieu e Sayad fornecem a base de uma estrutura migratória explicitamente frutífera. Em termos gerais, esta é uma abordagem que inclui uma ênfase na natureza profundamente social dos seres humanos; a importância de um foco relacional em oposição à uma análise de indivíduos ou grupos; como a cultura e o poder estão integralmente relacionados; as conexões entre etnia, racismo e classe; os padrões de mudança, de resistência e de resignação dos dominados; os contextos em que ocorrem modos de identificação e organização de grupos; a importância das classificações estaduais na definição da posição objetiva no espaço social dos migrantes, bem como a sua autopercepção; a importância da prática de exame - não apenas em termos de ver o que os atores fazem, ao contrário do que eles dizem - mas em termos de incorporar uma análise de seu corpo; e empregando um relato científico não-maniqueísta "relativamente separado" das relações sociais (ELIAS, 1987).

Tal abordagem nos permitirá gerar novos trabalhos empíricos sobre a migração e explicar as variadas formas de dominação etnoracial. Também pode nos fornecer uma base mais científica para uma prática política instruída, destinada a resistir à dominação social e à injustiça. 


\section{Referências}

ABRAMS, P. Notes on the Difficulty of Studying the State'. In: Journal of Historical

Sociology, v. 1, n. 1, 1988, pp. 58-89.

BARNES, B. Concept application as a social activity. Critica, v. 9, n. 56, 1988, pp. 19-46. BOURDIEU, P. The Algerians. Boston: Beacon Press, 1958 [1961].

. Revolution dans la revolution, Esprit, v. 1, 1961, pp. 27-40.

The Attitude of the Algerian Peasant Toward Time. In: Pitt-Rivers, Jesse (ed.),

Mediterranean Countrymen, Paris and The Hague, Mouton, 1964, pp. 55-72. 1

. Rethinking the state: genesis and structure of the bureaucratic field', Socio- lo-

gical Theory, v. 12, n. 1, 1994, pp. 1-18.

Distinction: A Social Critique of the Judgement of Taste. Oxford, Blackwell, 1984.

What makes a social class? On the theoretical and practical existence of groups.

Berkeley Journal of Sociology, v. 32, 1987, pp. 1-18.

The Logic of Practice, Cambridge, Polity Press, 1990a.

In Other Words. Cambridge, Polity, $1990 b$.

The Political Ontology of Martin Heidegger. Cambridge: Polity, 1991a.

Language and Symbolic Power. Cambridge: Polity, 1991b.

The State Nobility. Cambridge: Polity, 1996.

Practical Reason. Cambridge: Polity, 1998a.

Acts of resistance: Against the Tyranny of the Market, New York: New

Press, $1998 \mathrm{~b}$.

Preface. In: SAYAD, A. The Suffering of the Immigrant. Cambridge: Polity, 2004a. Algerian Landing, Ethnography, v. 5, n. 4, 2004b, pp. 415-442.

Equisse pour Une Auto-analyse. Paris : Raisons d'agir Editions, Cours et Travaux, 2004c.

From the king's house to the reason of the state: a model of the genesis of the

bureaucratic field. In: Constellations, v. 11, n. 1, 2004d, pp. 16-36.

BOURDIEU, P.; DARBEL, A. ; RIVET, J.-P. ; SEIBEL, C. Travail et travailleurs en

Algerie. Paris and The Hague: Mouton, 1963.

BOURDIEU, P.; SAYAD, A. Le Déracinement: La crise de l'agriculture traditionnelle en

Algerie. Paris : Editions de Minuit, 1964.

BOURDIEU, P.; SAYAD, A. Colonial Rule and Cultural Sabir. Ethnography, v. 5, n. 4, 2004 [1964], pp. 544-86.

BOURDIEU, P.; WACQUANT, L. The organic ethnologist of Algerian migration.

Ethnography, v. 1, n. 2, 2000, pp. 173-182. 
CORRIGAN, P.; SAYER, D. The Great Arch: state formation as cultural revolution.

Oxford: Blackwell, 1985.

ELIAS, N. What is Sociology? London: Hutchinson, 1978.

Involvement and Detachment. Oxford: Blackwell, 1987.

.; SCOTSON, J. The Established and Outsiders. London: Sage, 1994 [1968].

GOODMAN, N. Ways of Worldmaking. Indianapolis: Hacket publishing, 1978.

HACKING, I. Historical Ontology. Harvard: Harvard University Press, 2002.

HEARTFIELD, J. The Death of the Subject. Explained, Leicester, Perpetuity Press, 2002.

HONNETH, A., KOCYBA, H.; SCHWIBS, B. The struggle for symbolic order: an interview with Pierre Bourdieu. Theory, Culture and Society, v. 3, n. 3, 1986, 35-51.

HUSSERL, E. On the Phenomenology of the Consciousness of Internal Time. Boston:

Kluwer Academic Publishers, 1990.

KRIPKE, S. Naming and Necessity. Oxford, Blackwell, 1980.

LE SEUER, J. Uncivil War: Intellectuals and Identity Politics During the Decolonisation of Algeria. Lincoln: University of Nebraska Press, 2001.

LOYAL, S. The French in Algeria, Algerians in France: Bourdieu, colonialism and migration. Sociological Review, v. 57, no 3, 2009, pp. 406-28.

The Sociology of Anthony Giddens. London: Pluto, 2003.

Welcome to the Celtic Tiger, Immigration, Racism and the State. In: COULTER, C.; COLEMAN, S. (Eds). The End of Irish History. Manchester, Manchester University Press, 2003a.

MACMASTER, N. Colonial Migrants and Racism: Algerians in France 1900-1962, Basingstoke, MacMillan, 1997.

MANN, M. Nation-states in Europe and other continents diversifying, developing, not dying. Daedalus, v. 122, n. 3, 1993, pp. 115-140.

MANN, M. Has Globalisation ended the rise and rise of the nation-state? Review of International Political Economy, v. 4, n. 3, 1997, pp. 472-496.

PITKIN, H. The Concept of Representation, Berkeley, University of California, 1967.

FANON, F. A Dying Colonialism. New York: Grove Press, 1965.

HAMMAR, T. Democracy and the Nation-State: Aliens, Denizens and Citizens in a World of International Migration. Aldershot: Gower, 1990.

MERLEAU-PONTY, M. The Phenomenology of Perception. London: Routledge, 1962.

NOIRIEL, G. The French Melting Pot: Immigration, Citizenship and National Identity. Minneapolis : University of Minnesota Press, 1996.

SAYAD, A. Histoire et Recherche Identitaire. Paris: Bouchène, 1998. The Suffering of the Immigrant. Cambridge: Polity, 2004. 
SCOTT, M.; LYMAN, B. Account, Deviance and Social Order. In: DOUGLAS, J. Deviance and Respectability: The Social Construction of Moral Meanings. New York: Basic Books, 1970.

WACQUANT, L. For an analytic of racial domination. Political Power and Social Theory, V. 11, 1997, pp. 221-234.

Following Pierre Bourdieu into the Field. Ethnography, v. 5, n. 4, 2004, pp. 387-414.

WIMMER, A; GLICK-SCHILLER, N. Methodological Nationalism and beyond: Nation state building, migration and the social sciences. Global Networks: A Journal of Transnational Affairs, vol. 2, n. 4, 2002, pp. 301-334.

Recebido em 21/12/2017

Aprovado em 19/02/2018

\section{Como citar este artigo:}

LOYAL, Steven. Bourdieu, colonialismo e migração. Contemporânea - Revista de Sociologia da UFSCar, v. 8, n. 1, jan.- jun. 2018, pp. 11-138. 